\title{
Electrical resistivity and thermal properties of compatibilized multi-walled carbon nanotube/polypropylene composites
}

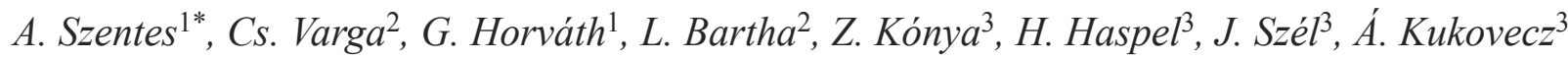 \\ ${ }^{1}$ University of Pannonia, Institutional Department of Chemical Engineering Science, H-8200 Veszprém, Egyetem u. 10 , \\ Hungary \\ ${ }^{2}$ University of Pannonia, Institutional Department of MOL Hydrocarbon and Coal Processing, H-8200 Veszprém, \\ Egyetem u. 10, Hungary \\ ${ }^{3}$ University of Szeged, Department of Applied and Environmental Chemistry, H-6720 Szeged, Rerrich Béla tér 1, \\ Hungary
}

Received 26 October 2011; accepted in revised form 15 January 2012

\begin{abstract}
The electrical resistivity and thermal properties of multi-walled carbon nanotube/polypropylene (MWCNT/PP) composites have been investigated in the presence of coupling agents applied for improving the compatibility between the nanotubes and the polymer. A novel olefin-maleic-anhydride copolymer and an olefin-maleic-anhydride copolymer based derivative have been used as compatibilizers to achieve better dispersion of MWCNTs in the polymer matrix. The composites have been produced by extrusion followed by injection moulding. They contained different amounts of MWCNTs ( 0.5 , 2, 3 and $5 \mathrm{wt} \%$ ) and coupling agent to enhance the interactions between the carbon nanotubes and the polymer. The electrical resistivity of the composites has been investigated by impedance spectroscopy, whereas their thermal properties have been determined using a thermal analyzer operating on the basis of the periodic thermal perturbation method. Rheological properties, BET-area and adsorption-desorption isotherms have been determined. Dispersion of MWCNTs in the polymer has been studied by scanning electron microscopy (SEM).
\end{abstract}

Keywords: polymer composites, multi-walled carbon nanotubes, polypropylene, electrical resistivity, thermal conductivity

\section{Introduction}

Carbon nanotubes (CNTs) are promising reinforcing fillers for polymers due to their excellent mechanical, electrical and thermal properties [1]. Recently the coupling of physical and mechanical properties particularly has achieved widespread interest in the area of carbon nanotube composites. Although polymer matrices of composites are generally considered as non-conductive materials because of their extremely low electrical conductivity, conductive polymer composites can be formed by application of conductive fillers, like CNTs [26]. Electrical conductivity of the composite is highly dependent on the volume fraction of the conductive phase. There is a lower limit for volume fraction of the filler, called percolation threshold, at which conductivity of the composite increases by many orders of magnitude. Depending on the matrix, the processing technique, and the nanotube type, wide ( 0.001 to $10 \mathrm{wt} \%)$ range of percolation thresholds has been reported in the literature so far [6]. Low values for percolation threshold can be achieved by a well-dispersed structure of CNTs in the polymer matrix.

Howewer, commercial application of CNTs by the plastics industry has been limited so far because they are difficult to disperse in polymer matrices. Inhomogeneous CNT dispersion results in the sig-

\footnotetext{
${ }^{*}$ Corresponding author, e-mail: szentesa@almos.uni-pannon.hu
} (c) BME-PT 
nificant deterioration of the mechanical properties of the end-product [1], therefore, it is important to reduce the agglomeration and increase the dispersion of carbon nanotubes, thus achieving a homogeneous distribution of the nanotubes in the polymer matrix. The latter is important in order to avoid the deterioration of the mechanical and functional properties of carbon nanotube polymer composites $[7,8]$.

Carbon nanotubes are non-polar materials containing only a few functional groups that could react with polymers, therefore, different methods have been developed to achieve stronger interaction between carbon nanotubes and polymers. Modification methods of CNTs can be divided into two main categories based on the type of bonding to the nanotube surface. Non-covalent modification means the physical adsorption and/or wrapping of polymers to the surface of CNTs. The graphitic walls of CNTs provide the possibility for $\pi$-stacking interactions with conjugated polymers as well as with polymers containing heteroatoms possessing at least one free electron pair. On the other hand, covalent bonding (grafting) of polymer chains to the CNTs corresponds to establishing strong chemical bonds between the nanotubes and the polymer. Grafting is either 'grafting to' or 'grafting from'. In the first case a polymer with reactive end-groups can be bonded to the CNT, whereas in the latter case monomers can be reacted with the surface in the presence of radical initiators followed by the polymerization reaction of the monomers.

The advantage of non-covalent functionalization is that the interaction does not perturb the structure of the carbon nanotubes, because additives only adhere to the surface of the nanotubes, therefore, the advantageous CNT properties originating from the continuous $s p^{2}$ hybrid structure are retained [911]. Additives used for non-covalent functionalization of CNTs are referred to as coupling agents or compatibilizers. Their function is to establish proper interaction between carbon nanotubes and polymer matrix and to prevent the formation of nanotube agglomerates, therefore, they are chosen on the basis of the chemical composition of the reinforcing material and the polymer.

There are several well-known types of compatibilizers, for example maleic-anhydride grafted polyolefins (MA-g-PO) or silane type additives are gen- erally applied to enhance the compatibility of glass or carbon fibers both with thermoplastics and thermosets [12-14]. Maleic-anhydride grafted polymers can be only blended to the polymer/nanotube mixture, therefore only the dispersion of the CNTs can be improved $[15,16]$ but CNT/polymer interaction cannot be significantly modified. For improving the bonding between them special methods are required that are able to establish strong connection between functional groups.

In this contribution we report on the applicability of a new olefin-maleic-anhydride copolymer and its ester-amide derivative for enhancing the compatibility of multi-walled carbon nanotubes with a polypropylene matrix based on previously successful results in carbon fiber reinforced polyolefin and glass fiber reinforced polyester composites [17-19]. The novel aspect of our work is that the MWCNTs were synthesized by our proprietary heterogeneous catalytic method which has been scaled up successfully at the University of Pannonia, Hungary. This method has been specifically designed to produce large quantities of cheap MWCNTs for polymer filler applications and therefore, the catalyst support talc (approx. $10 \mathrm{wt} \%$ ) is not removed from the product at all. The electrical and thermal properties of the synthesized composites are compared with reference samples containing carbon black, commercial Nanocyl MWCNTs and carbon-free talc. We will demonstrate that the behavior of composites containing cheap MWCNT/talc nanotubes compares favourably with that of composites based on more expensive commercial carbon nanotubes.

\section{Experimental}

\subsection{Materials}

Multi-walled carbon nanotubes (MWCNT) were produced at $700^{\circ} \mathrm{C}$ by chemical vapor deposition (CVD) process over $\mathrm{Fe}-\mathrm{Co}$ bimetallic catalyst at the Institutional Department of Chemical Engineering (Institute of Chemical and Process Engineering, University of Pannonia, Veszprém, Hungary) [20]. Their diameter was between 10 and $20 \mathrm{~nm}$ and their average length was above $30 \mu \mathrm{m}$. The synthesized nanotubes were not separated from the talc support, thus the produced filler material (denoted as UPNT from now on) consisted of $90 \mathrm{wt} \%$ MWCNTs and $10 \mathrm{wt} \%$ talc. Polypropylene (PP) homopolymer (H116F, TVK Plc, Tiszaújváros, Hungary melt flow 


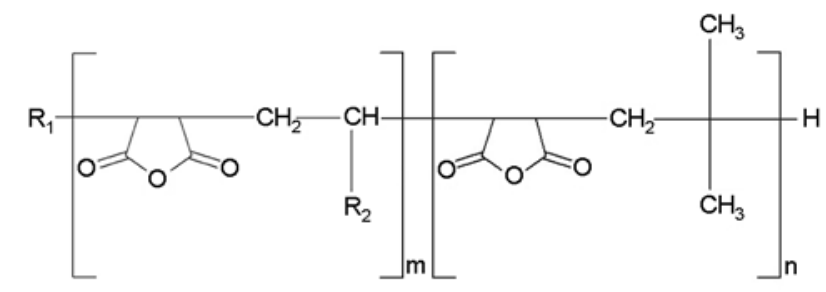

a)

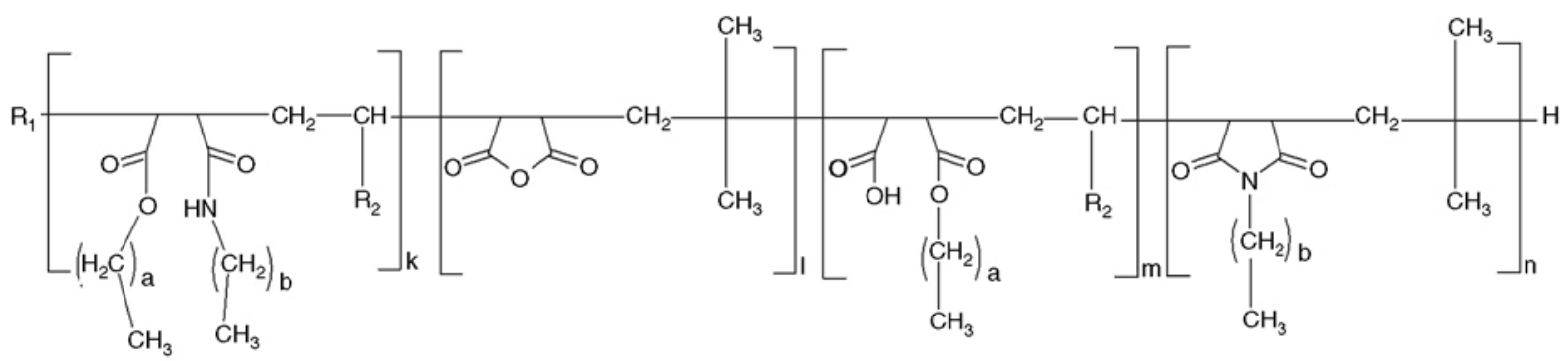

b)

Figure 1. Structure of the olefin-maleic-anhydride copolymer (OMA) where $\mathrm{R}_{1}$ : alkyl chain with length of the olefinic monomer; $\mathrm{R}_{2}$ : alkyl chain with $\mathrm{R}_{1-2}$ carbon number; $m, n: 5-9$ (a) and structure of the olefin-maleic-anhydrideester-amide copolymer (OMAEA) where $\mathrm{R}_{1}$ : alkyl chain with length of the olefinic monomer; $\mathrm{R}_{2}$ : alkyl chain with $\mathrm{R}_{1-2}$ carbon number; $a, b: 2-21 ; k: 0.2-2 ; 1: 1-7 ; m: 1-7$ and $n: 0.3-2$ (b)

rate $28.0 \mathrm{~g} / 10 \mathrm{~min}$ at $190^{\circ} \mathrm{C}, 2.16 \mathrm{~kg}$ ) was used as the matrix material. An olefin-maleic-anhydride copolymer (OMA) (Figure 1a) and an olefin-maleicanhydride-ester-amide (OMAEA) (Figure 1b) were used as compatibilizers. Both were synthesized at the Institutional Department of MOL Hydrocarbon and Coal Processing (Institute of Chemical and Process Engineering, University of Pannonia).

Multi-walled carbon nanotubes from Nanocyl S. A. Belgium (NC7000: MWCNT $90 \mathrm{wt} \%$ carbon purity for industrial applications, signed by ' $\mathrm{NC}$ ' in the followings), talc (Thomasker Finechemicals Ltd, Hungary) and carbon black (denoted as CB, type K354, purchased from Carbon Black Ltd, Hungary) were used as reference materials.

\subsection{Preparation of composites}

The composition of all compatibilizer-free PP composites is summarized in Table 1. In order to compare composites filled with carbon materials in different forms, not only our CNT product (UPNT) was introduced into PP matrix but also carbon black (CB) and commercially available CNT (NC) were applied. As UPNT contained talc as a catalyst carrier in $10 \mathrm{wt} \%$, composites filled with that talc content were also produced. Nanocyl MWCNTs contained $10 \mathrm{wt} \%$ undisclosed catalyst support material according to the product datasheet. This was also
Table 1. Composition of the compatibilizer-free PP composites

\begin{tabular}{|l|c|c|c|c|}
\hline \multicolumn{1}{|c|}{ Sample } & $\begin{array}{c}\text { PP } \\
{[\mathbf{w t} \%]}\end{array}$ & $\begin{array}{c}\text { MWCNT } \\
{[\mathbf{w t} \%]}\end{array}$ & $\begin{array}{c}\text { Carbon } \\
\text { black } \\
{[\mathbf{w t} \%]}\end{array}$ & $\begin{array}{c}\text { Talc } \\
\text { (or *other) } \\
{[\mathbf{w t} \text { \%] }}\end{array}$ \\
\hline $\mathrm{PP}$ & 100 & & & \\
\hline $\mathrm{PP} / \mathrm{UPNT} / 0.5$ & 99.5 & 0.45 & & 0.05 \\
\hline $\mathrm{PP} / \mathrm{UPNT} / 2$ & 98 & 1.8 & & 0.2 \\
\hline $\mathrm{PP} / \mathrm{UPNT} / 3$ & 97 & 2.7 & & 0.3 \\
\hline $\mathrm{PP} / \mathrm{UPNT} / 5$ & 95 & 4.5 & & 0.5 \\
\hline $\mathrm{PP} / \mathrm{NC} / 0.5$ & 99.5 & 0.45 & & $* 0.05$ \\
\hline $\mathrm{PP} / \mathrm{NC} / 2$ & 98 & 1.8 & & ${ }^{*} 0.2$ \\
\hline $\mathrm{PP} / \mathrm{NC} / 3$ & 97 & 2.7 & & $* 0.3$ \\
\hline $\mathrm{PP} / \mathrm{NC} / 5$ & 95 & 4.5 & & $* 0.5$ \\
\hline $\mathrm{PP} / \mathrm{CB} /$ talc/0.5 & 99.5 & & 0.45 & 0.05 \\
\hline $\mathrm{PP} / \mathrm{CB} / \mathrm{talc} / 2$ & 98 & & 1.8 & 0.2 \\
\hline $\mathrm{PP} / \mathrm{CB} /$ talc/3 & 97 & & 2.7 & 0.3 \\
\hline $\mathrm{PP} / \mathrm{CB} /$ talc/5 & 95 & & 4.5 & 0.5 \\
\hline
\end{tabular}

taken into account in Table 1 in the rows marked with an asterisk (*other).

Coupling agents (OMA and OMAEA) were tested in PP/UPNT composites using two different application methods. In the masterbatch method (MB) a masterbatch was produced from the coupling agent and $\mathrm{PP}$ in 1:9 mass ratio then the masterbatch was mixed with the neat PP and UPNT in a twin-screw extruder.

In the impregnation method (IM) the surface of UPNT was covered by the coupling agent from the 
Table 2. Composition of the compatibilized carbon nanotube/polypropylene composites

\begin{tabular}{|l|l|c|c|c|}
\hline \multicolumn{1}{|c|}{ Sample } & $\begin{array}{c}\text { PP } \\
{[\mathbf{w t} \%]}\end{array}$ & $\begin{array}{c}\text { UPNT } \\
{[\mathbf{w t} \%]}\end{array}$ & $\begin{array}{c}\text { OMA } \\
{[\mathbf{w t} \%]}\end{array}$ & $\begin{array}{c}\text { OMAEA } \\
{[\mathbf{w t} \text { \%] }}\end{array}$ \\
\hline OMA/MB/0.5 & 99.45 & 0.5 & 0.05 & \\
\hline OMA/MB/2 & 97.8 & 2 & 0.2 & \\
\hline OMA/MB/3 & 96.7 & 3 & 0.3 & \\
\hline OMA/MB/5 & 94.5 & 5 & 0.5 & \\
\hline OMAEA/MB/0.5 & 99.45 & 0.5 & & 0.05 \\
\hline OMAEA/MB/2 & 97.8 & 2 & & 0.2 \\
\hline OMAEA/MB/3 & 96.7 & 3 & & 0.3 \\
\hline OMAEA/MB/5 & 94.5 & 5 & & 0.5 \\
\hline OMA/IM/0.5 & 99.45 & 0.5 & 0.05 & \\
\hline OMA/IM/2 & 97.8 & 2 & 0.2 & \\
\hline OMA/IM/3 & 96.7 & 3 & 0.3 & \\
\hline OMA/IM/5 & 94.5 & 5 & 0.5 & \\
\hline OMAEA/IM/0.5 & 99.45 & 0.5 & & 0.05 \\
\hline OMAEA/IM/2 & 97.8 & 2 & & 0.2 \\
\hline OMAEA/IM/3 & 96.7 & 3 & & 0.3 \\
\hline OMAEA/IM/5 & 94.5 & 5 & & 0.5 \\
\hline
\end{tabular}

hydrocarbon solution of the additive with stirring of the mixture for 1 hour at $60^{\circ} \mathrm{C}$. The solvent was subsequently evaporated; the treated UPNTs were dried at $110^{\circ} \mathrm{C}$ for 2 hours in air and were finally introduced into the neat polymer in the twin-screw extruder. Compounds were prepared by extrusion. A twin-screw extruder was applied with different zone temperatures $\left(195,200,205,210^{\circ} \mathrm{C}\right)$ for introducing the fillers into the polymer. Dog-bone samples for testing were injection-moulded.

Specimens for electrical and thermal measurements were also injection-moulded. Compositions of the PP/UPNT composites containing coupling agents are summarized in Table 2.

\subsection{Characterization}

The electrical resistivity $(\rho[\Omega \mathrm{m}])$ of the composites was determined in the $10^{-1}-10^{7} \mathrm{~Hz}$ frequency range using a Novocontrol Alpha-A (Novocontrol, Hundsangen, Germany) modular measurement system connected to a ZG2 2-wire impedance interface and a BDS1200 sample holder. The electrical contact between the sample and the instrument was improved by sputtering a $20 \mathrm{~nm}$ thick silver film onto both sides of the thin sample disks using a Polaron SC7620 Mini Sputter Coater (Quorum Technologies, Ashford, UK). The complex impedance of the samples was measured in capacitor geometry and converted to specific electrical resistance by taking the geometry of the sample into account.
The thermal conductivity and thermal diffusivity of thin sample disks were determined simultaneously in a purpose-built instrument utilizing the periodic thermal perturbation method. In this technique the sample disk is sandwiched between two copper blocks in vacuum and the temperature of the bottom block is continuously modulated by a sum of several sinusoid thermal waves of different frequencies. As these waves travel across the sample their amplitude is reduced and their phase is shifted as determined by the thermal properties of the studied material. By monitoring the temperature of the upper block as a function of time and Fourier transforming this signal to obtain the propagation properties of the individual thermal waves it is possible to calculate the heat transfer function of the sample, which in turn can be used to calculate the thermal conductivity and thermal diffusivity [21].

The specific surface area and pore size distribution in the micropore, mesopore, and macropore diameter ranges were determined by nitrogen adsorption/ desorption isotherms measured with a Micromeritics ASAP 2000-type instrument (Micromeritics, Aachen, Germany). The samples previously gassed out in vacuum at the temperature of $100^{\circ} \mathrm{C}$. The surface areas of the samples were determined by the BET method from the corresponding nitrogen adsorption isotherm [22]. The meso and macropore volume values were calculated from the nitrogen desorption isotherms using the BJH (Barret-JoynerHalenda) theory [23].

Rheological measurements were carried out by a Smart Rheo 2000 (CEAST, Italy) capillary rheometer at $210^{\circ} \mathrm{C}$ in 2 to $1500 \mathrm{l} / \mathrm{s}$ shear rate range.

The composite fracture surfaces were characterized by scanning electron microscopy (SEM) using a Hitachi S-4700 Type II cold field emission instrument (Hitachi, Tokyo, Japan). Samples for SEM were coated with a thin $(<4 \mathrm{~nm})$ gold-palladium layer deposited by argon plasma sputter coating to avoid charging effects.

\section{Results and discussion}

\subsection{Electrical resistivity of the composites}

The electrical resistivity of a MWCNT/polymer composite depends on the size, shape, concentration, distribution and surface treatment of nanotubes [24]. In Figure 2 the effect of all tested fillers on the electrical resistivity of compatibilizer-free 


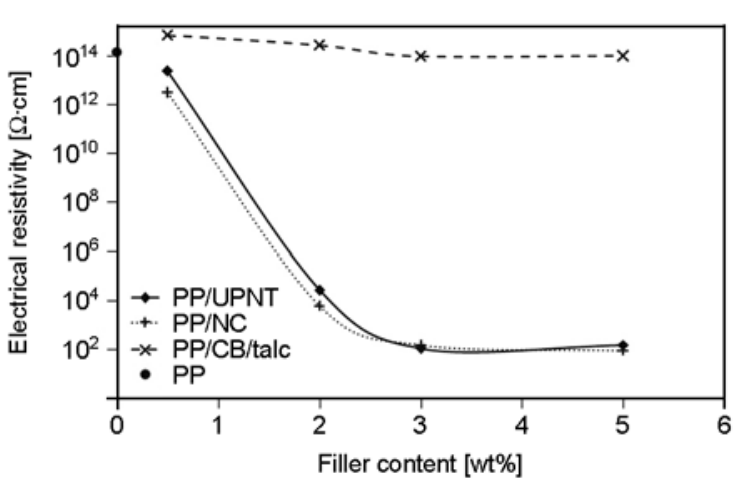

Figure 2. Electrical resistivity of the compatibilizer-free polypropylene composites

polypropylene is depicted for various filler concentrations $(0.5,2,3$ and $5 \mathrm{wt} \%)$.

It is evident from Figure 2 that while neat PP exhibits very high electrical resistivity $\left(1.43 \cdot 10^{14} \Omega \mathrm{cm}\right)$, this can be decreased significantly by introducing CNTs into the polymer. At low nanotube contents a proper percolating network structure could not be established in the polymer matrix, therefore, the electrical resistivity of those samples remained high. When increasing the filler content above $2 \mathrm{wt} \%$ a continuous nanotube network was obtained as indicated by the significant drop in the resistivity. The electrical resistivity of $2 \mathrm{wt} \%$ UPNT containing composite was $2.61 \cdot 10^{4} \Omega \mathrm{cm}$. It is worth noting that adding more MWCNTs to the composite above the threshold concentration level of approx. $3 \mathrm{wt} \%$ cannot improve the conductivity any further. The $\mathrm{PP} / \mathrm{UPNT}$ and PP/NC composites exhibited very similar behavior in the whole concentration range. The nanotube-related origin of the improved electrical conductivity was confirmed by the lack of resistivity decrease in the case of $\mathrm{PP} /$ carbon black/ talc composites. Further studies would be necessary to uncover the reasons of the minor resistivity increase relative to PP observed for low carbon black/talc concentration levels. The most plausible explanation is that although the filler did not actually modify the electrical conductivity of the composite, it affected the density of the samples and this translated into a slight resistivity increase when calculating the specific resistivity from the raw impedance data.

In Figure 3 the effect of the coupling agents on the electrical resistivity of $\mathrm{PP} / \mathrm{CNT}$ composites is depicted. The general trends identified for compatibilizer-free samples can be observed here as well.

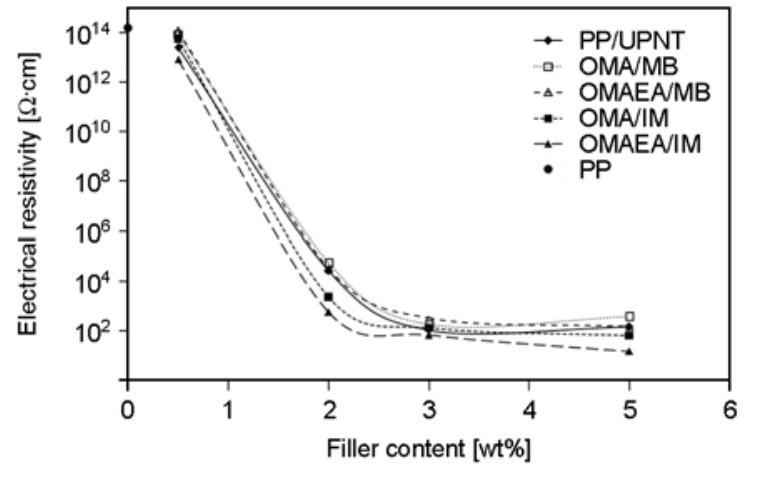

Figure 3. Electrical resistivity of compatibilized carbon nanotube/polypropylene composites

However, composites produced by the masterbatch method (OMA/MB and OMAEA/MB) exhibited resistivities that were several times higher than those measured on the corresponding impregnation method samples or compatibilizer-free PP/CNT composites. On the other hand, the impregnation method offered approx. one order of magnitude improvement in electrical conductivity over the corresponding pristine PP/CNT composites. Summarizing, it appears that simply blending the coupling agent into the polymer matrix hinders the nanotube-tonanotube electron transfer, whereas immobilizing it on the carbon nanotube surface (impregnation method) actually promotes conduction.

The electrical resistivity of masterbatch samples was practically independent of the chemical structure of the coupling agent. This was not the case for impregnated samples, as the conductivity of OMAEA/ IM samples was higher than that of OMA/IM samples. The electrical resistivity of the OMAEA/IM sample was $570 \Omega \mathrm{cm}$, while that of OMA/IM samples was $2250 \Omega \mathrm{cm}$ in case of $2 \mathrm{wt} \%$ CNT content. Further investigations are necessary to uncover the exact role of the anhydride, half-ester, imide and ester-amide functional groups in the conductivity improvement process.

\subsection{Thermal properties of the composites}

The thermal conductivity coefficient $(k[\mathrm{~W} /(\mathrm{mK})])$ of polypropylene was found to be independent of the carbon black and talc concentration (Figure 4). On the other hand, adding carbon nanotubes to the polymer improved its thermal conductivity as a linear function of CNT content. UPNT nanotubes performed significantly better than the reference NC nanotubes as indicated by the steeper slope of the 


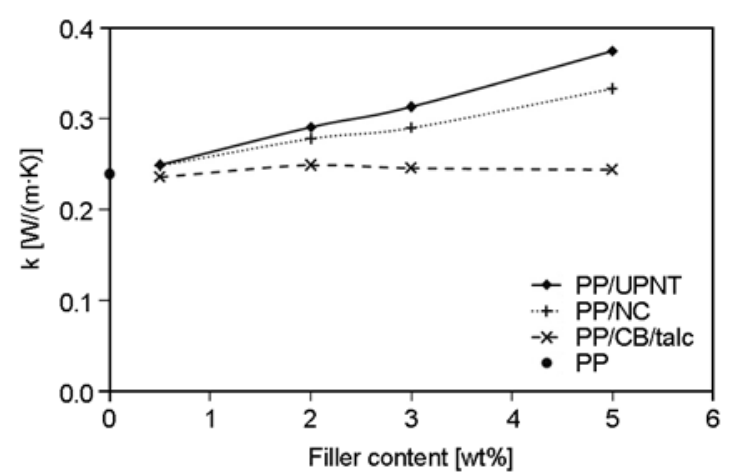

Figure 4. The thermal conductivity coefficient of compatibilizer-free polypropylene composites

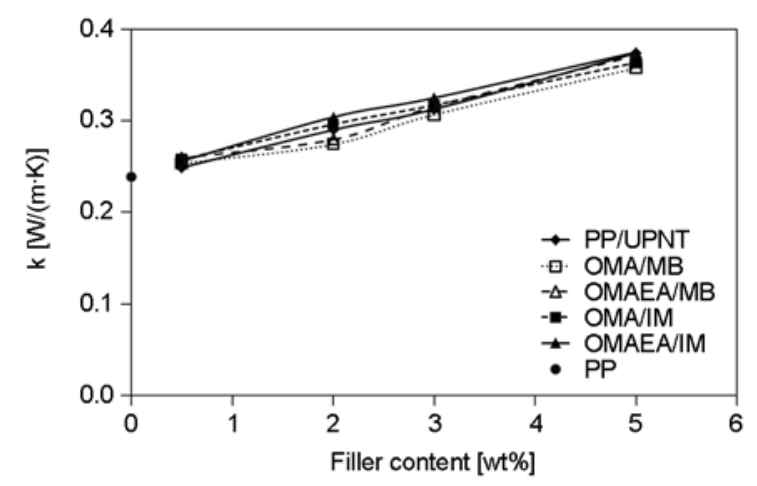

Figure 5. The thermal conductivity coefficient of compatibilized carbon nanotube/polypropylene composites

corresponding curve in Figure 4. For example, the thermal conductivity coefficient was $0.332 \mathrm{~W} /(\mathrm{mK})$ for $\mathrm{NC}$ and $0.374 \mathrm{~W} /(\mathrm{mK})$ for UPNT at $5 \mathrm{wt} \%$ nanotube concentration, which meant 40 and $57 \%$ thermal conductivity increase relative to PP $(0.238 \mathrm{~W} /(\mathrm{mK}))$.

Neither the chemical structure nor the application method of the coupling agent affected the thermal conductivity of the composites. Figure 5 shows that thermal conductivity coefficient values measured for different materials at the same CNT content agreed within $\pm 5 \%$.

\subsection{Effects of surface treatment}

Effects of treatment on the properties of CNTs were also studied. BET-area and adsorption-desorption isotherms of untreated UPNT and additive treated UPNT (OMAEA/IM) were determined (Figure 6). BET-area of the pristine UPNT was $180.9 \mathrm{~m}^{2} / \mathrm{g}$, whereas for surface treated UPNT $91.1 \mathrm{~m}^{2} / \mathrm{g}$ value was measured. Treatment with the coupling agent had a significant influence on the isotherms of the CNTs unambiguously due to the coupling agent. Capability of CNT for gas adsorption decreased by

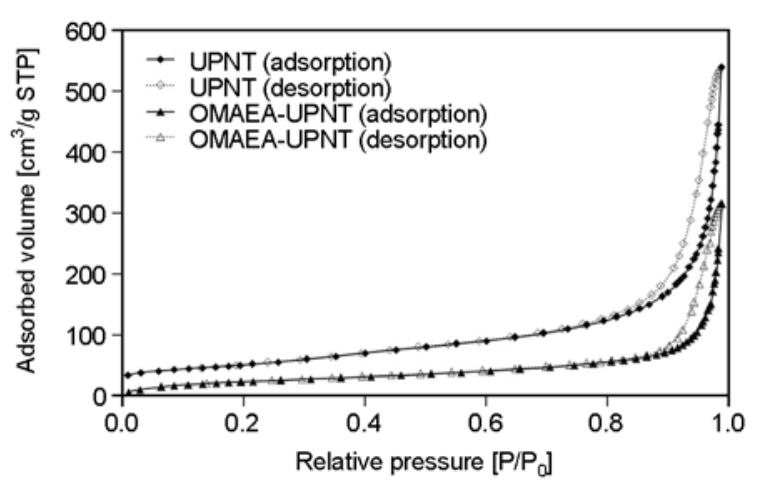

Figure 6. Adsorption-desorption isotherms of UPNT and OMAEA additive treated UPNT

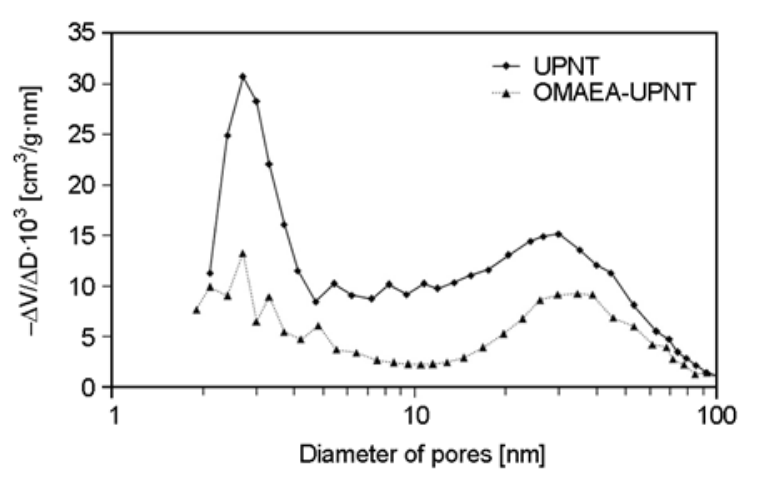

Figure 7. Distribution of diameter of mesopores

$40 \%$ when the additive was connected to the surface. Difference between the isotherms of pristine CNT and additive treated CNT did not change in the whole investigated pressure range. Additive sizing on the CNT was stable even at $100^{\circ} \mathrm{C}$ temperature since the coupling agent could not be removed from the surface even in vacuum.

Regarding the distribution of diameter of mesopores (Figure 7) the additive seemed to shield the smaller pores with diameter of $2.5-4.0 \mathrm{~nm}$. That could be one reason for the additive treated CNT not to hinder the transfer of the electrons in the composites because the additive could be found on the surface. The connection of the additive to the surface could be one reason for better electron transfer in treated PP/CNT composites.

\subsection{Rheological properties of composites}

Rheological properties can reflect the structure of nanotube-containing composites and provide information about the interaction between the nanoparticles and the polymer matrix. Therefore evaluation of rheological behaviour of the composites is important in order to understand the effect of nanotubes on the structure [24]. 
We measured the viscosity of PP composites containing $2 \mathrm{wt} \%$ UPNT nanotubes and depicted the results in Figure 8. In agreement with received wisdom, adding nanotubes to PP without a coupling agent increased its viscosity [24-28]. Composites produced with nanotubes and OMAEA compatibilizer (OMAEA/MB) all featured lower viscosities

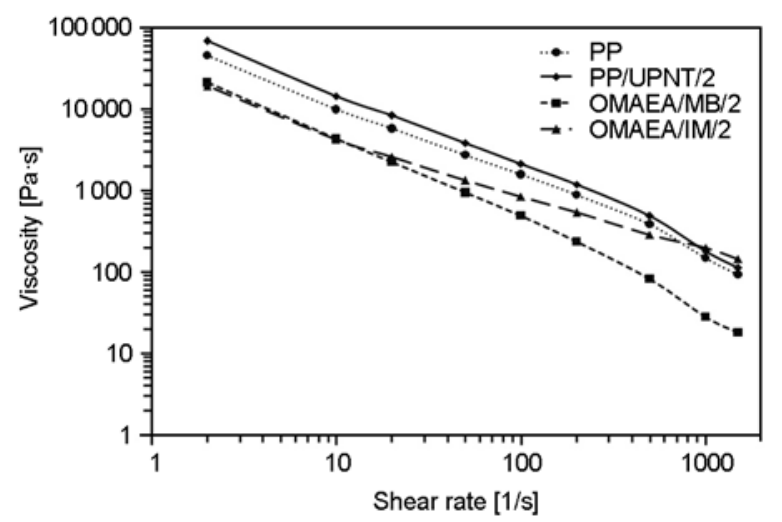

Figure 8. Comparison of rheological properties of composites containing coupling agents than their compatibilizer-free counterparts $(\mathrm{PP} /$ UPNT) because of the plasticizing effect of the additive. At low shear rates the effect was observable for both composite preparation methods. Whereas the masterbatch samples maintained this viscosity decrease in the whole studied shear rate range, composites prepared by OMAEA impregnation exhibited a more complex behaviour. They resembled masterbatch samples at low shear rates and compatibilizer-free PP/UPNT composites at high shear rates.

\subsection{Investigation by SEM}

Dispersion state of carbon nanotubes in the PP matrix was investigated by scanning electron microscopy (SEM). SEM images were taken of the composites filled with $2 \mathrm{wt} \%$ carbon nanotubes. Pristine carbon nanotubes (UPNT) seemed to form agglomerates (Figure 9a-9c). Lumps can be seen in certain locations at the surface of the composites. In

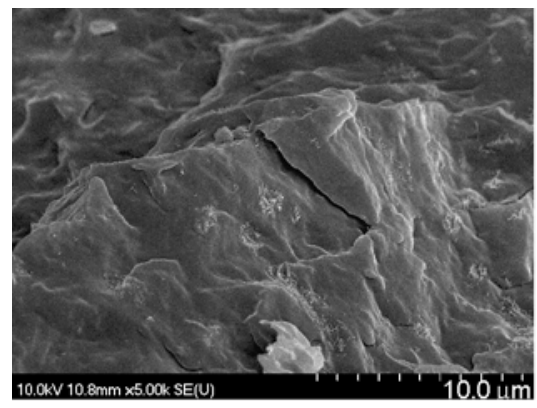

a)

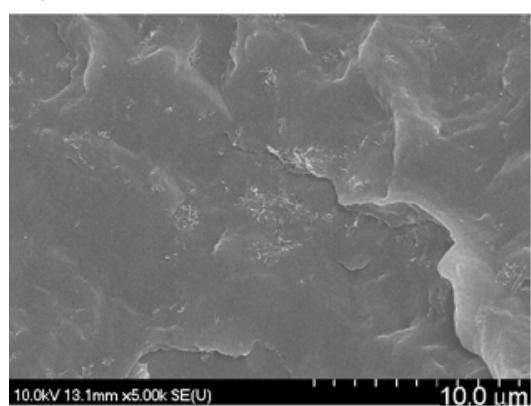

d)

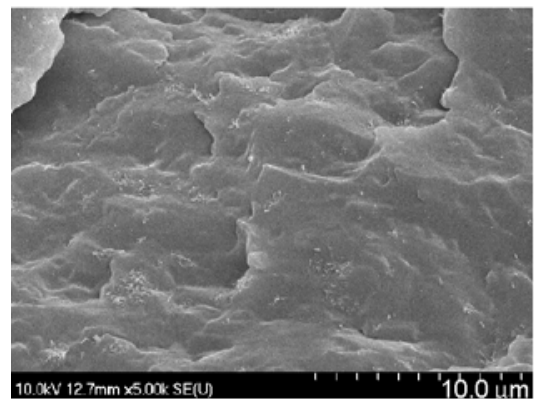

g)

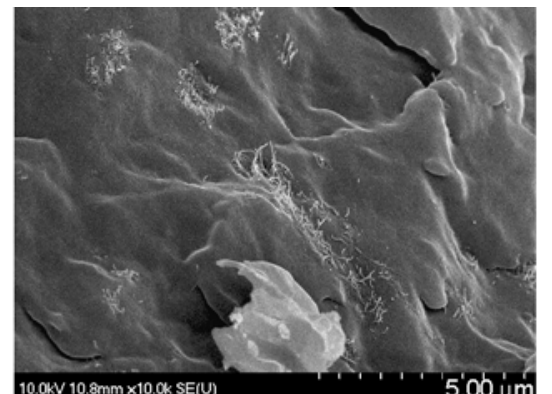

b)

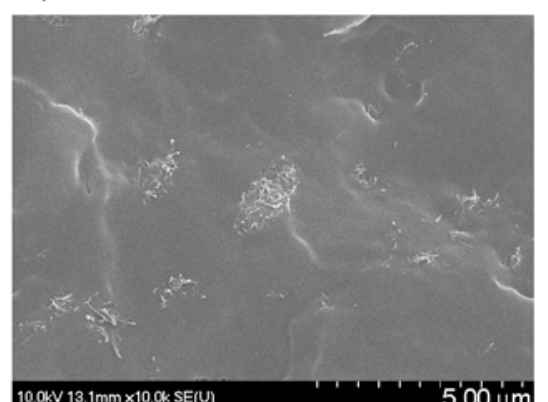

e)

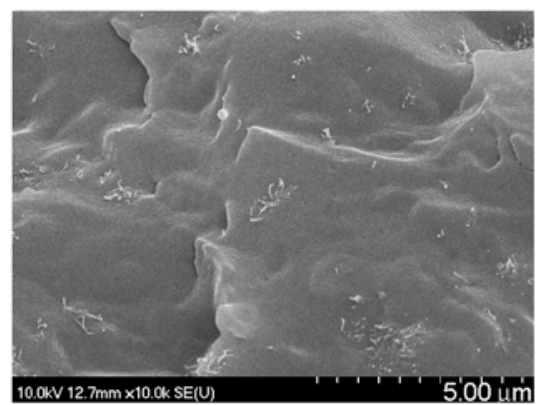

h)

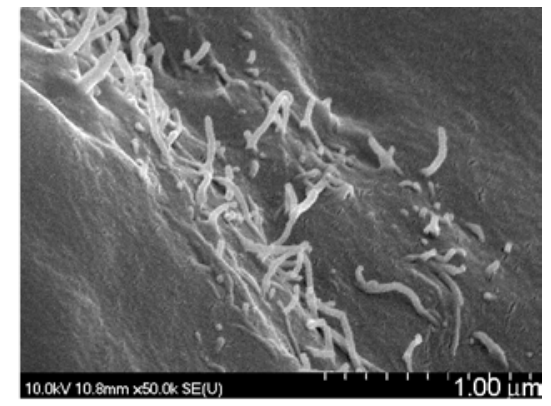

c)

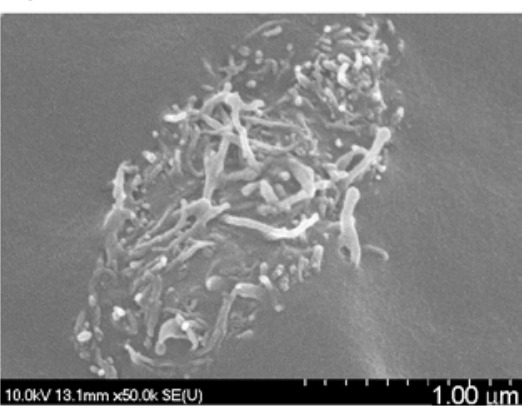

f)

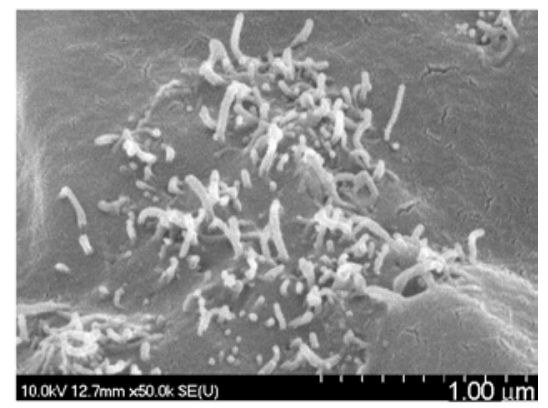

i)

Figure 9. SEM image of samples PP/UPNT/2 (a, b, c), OMAEA/MB/2 (d, e, f), OMAEA/IM/2 (g, h, i) 
case of $\mathrm{PP} / \mathrm{CNT}$ composites produced by masterbatch preparation method, tendency of the CNTs to agglomerate seemed to be lower as lumps were smaller, and more homogeneous dispersion of CNTs in the polymer could be achieved (Figure 9d9f). Slightly better dispersion could be obtained by application of surface-treated CNTs as significantly smaller aggregates could be observed on the surface of the composite (Figure 9g-9i).

\section{Conclusions}

New types of coupling agents were synthesized and applied for enhancing the interaction between talc supported multi-walled carbon nanotubes and PP. In this first presentation of the research basic electrical, thermal and rheological properties of the $\mathrm{PP} / \mathrm{CNT}$ composites were investigated. The following conclusions were drawn on the basis of the measured data:

- Electrically, the UPNT (talc supported MWCNT produced at University of Pannonia) and the NC (industrial grade commercial MWCNT produced by Nanocyl) carbon nanotubes exhibited very similar behaviour as polypropylene fillers. Carbon nanotubes can lower the electrical resistivity of polypropylene considerably. The electrical conductivity percolation threshold in the polymer matrix is approx. $2 \mathrm{wt} \%$ for both nanotube types.

- Introducing the coupling agent into the composite by the impregnation method is advantageous from the electrical resistivity point of view, but the way of blending the additives with the CNT and the polymer was not a successful method for improving the properties.

- The properties of OMAEA-compatibilized PP/ MWCNT composites are either superior (e.g. electrical conductivity) to those prepared by OMA coupling or are at least at the same level (e.g. thermal conductivity increase). Therefore, OMAEA appears to be a better overall coupling agent choice for polypropylene and talc-supported MWCNTs.

- The thermal conductivity of polypropylene can be improved by adding carbon nanotubes into the matrix. UPNT nanotubes outperformed commercial $\mathrm{NC}$ nanotubes by $17 \%$ in this respect. Unlike in the case of electrical conductivity, thermal conductivity does not saturate at approx. $2 \mathrm{wt} \%$
CNT concentration but rather, it keeps increasing as a quasi linear function of the nanotube contents of the sample. Neither the introduction method nor the chemical structure of the compatibilizer affects the thermal conductivity of the $\mathrm{PP} /$ coupling agent/MWCNT composites significantly.

- The tendency to agglomeration of CNTs decreased due to surface treatment according to SEM graphs of the composites, which could probably be related to the coupling agent interacting in the smaller diameter of pores on the CNT surface.

\section{Acknowledgements}

We acknowledge the financial support of this work by the Hungarian State and the European Union under the TAMOP4.2.1/B-09/1/KONV-2010-0003 project.

\section{References}

[1] Coleman J. N., Khan U., Blau W. J., Gun'ko Y. K.: Small but strong: A review of the mechanical properties of carbon nanotube-polymer composites. Carbon, 44, 1624-1652 (2006).

DOI: $10.1016 /$ j.carbon.2006.02.038

[2] Krause B., Pötschke P., Häußler L.: Influence of small scale melt mixing conditions on electrical resistivity of carbon nanotube-polyamide composites. Composites Science and Technology, 69, 1505-1515 (2009).

DOI: 10.1016/j.compscitech.2008.07.007

[3] Bao H-D., Guo Z-X., Yu J.: Effect of electrically inert particulate filler on electrical resistivity of polymer/ multi-walled carbon nanotube composites. Polymer, 49, 3826-3831 (2008).

DOI: 10.1016/j.polymer.2008.06.024

[4] Spitalsky Z., Tasis D., Papagelis K., Galiotis C.: Carbon nanotube-polymer composites: Chemistry, processing, mechanical and electrical properties. Progress in Polymer Science, 35, 357-401 (2009).

DOI: 10.1016/j.progpolymsci.2009.09.003

[5] Ounaies Z., Park C., Wise K. E., Siochi E. J., Harrison J. S.: Electrical properties of single wall carbon nanotube reinforced polyimide composites. Composites Science and Technology, 63, 1637-1646 (2003). DOI: $10.1016 / \mathrm{S} 0266-3538(03) 00067-8$

[6] Li C., Thostenson E. T., Chou T-W.: Sensors and actuators based on carbon nanotubes and their composites: A review. Composites Science and Technology, 68, 1227-1249 (2008).

DOI: 10.1016/j.compscitech.2008.01.006

[7] Breuer O., Sundararaj U.: Big returns from small fibers: A review of polymer/carbon nanotube composites. Polymer Composites, 25, 630-645 (2004).

DOI: $10.1002 / p c .20058$ 
[8] Moniruzzaman M., Winey K. I.: Polymer nanocomposites containing carbon nanotubes. Macromolecules, 39, 5194-5205 (2006).

DOI: $10.1021 / \mathrm{ma} 060733 \mathrm{p}$

[9] Wang C., Guo Z-X., Fu S., Wu W., Zhu D.: Polymers containing fullerene or carbon nanotube structures. Progress in Polymer Science, 29, 1079-1141 (2004). DOI: $10.1016 /$ j.progpolymsci.2004.08.001

[10] Liu P.: Modifications of carbon nanotubes with polymers. European Polymer Journal, 41, 2693-2703 (2005). DOI: $10.1016 /$ j.eurpolymj.2005.05.017

[11] Homenick C. M., Lawson G., Adronov A.: Polymer grafting of carbon nanotubes using living free-radical polymerization. Polymer Reviews, 47, 265-290 (2007). DOI: $10.1080 / 15583720701271237$

[12] Dutra R. C. L., Soares B. G., Campos E. A., Silva J. L. G.: Hybrid composites based on polypropylene and carbon fiber and epoxy matrix. Polymer, 41, 38413849 (2000).

DOI: 10.1016/S0032-3861(99)00552-2

[13] Wonderly C., Grenestedt J., Fernlund G., Cěpus E.: Comparison of mechanical properties of glass fiber/ vinyl ester and carbon fiber/vinyl ester composites. Composites Part B: Engineering, 36, 417-426 (2005). DOI: 10.1016/j.compositesb.2005.01.004

[14] Yang Y., Lu C-X., Su X-L., Wu G-P., Wang X-K.: Effect of nano- $\mathrm{SiO}_{2}$ modified emulsion sizing on the interfacial adhesion of carbon fibers reinforced composites. Materials Letters, 61, 3601-3604 (2007). DOI: $10.1016 /$ j.matlet.2006.11.121

[15] Xie X. L., Aloys K., Zhou X. P., Zeng F. D.: Ultrahigh molecular mass polyethylene/carbon nanotube composites crystallization and melting properties. Journal of Thermal Analysis and Calorimetry, 74, 317-323 (2003).

DOI: 10.1023/A:1026362727368

[16] Zhou X. P., Xie X. L., Zeng F., Li R. K. Y., Mai Y. W.: Properties of polypropylene/carbon nanotube composites compatibilized by maleic anhydride grafted SEBS. Key Engineering Materials, 312, 223-228 (2006). DOI: 10.4028/www.scientific.net/KEM.312.223

[17] Varga Cs., Miskolczi N., Szakács H., Lipóczi G.: Effects of industrial scale production on the chemical composition of novel coupling agents and its relationship to the mechanical properties of chopped glass fibre mat reinforced thermoset composites. Materials and Design, 32, 12-20 (2011). DOI: $10.1016 / \mathrm{j}$. matdes.2010.06.046

[18] Varga Cs., Miskolczi N., Bartha L., Lipóczi G., Falussy L.: Improving the compatibility of man-made fibre reinforced composites. Hungarian Journal of Industrial Chemistry, 36, 137-142 (2008).
[19] Varga Cs., Miskolczi N., Bartha L., Lipóczi G.: Improving the mechanical properties of glass-fibrereinforced polyester composites by modification of fibre surface. Materials and Design, 31, 185-193 (2010).

DOI: $10.1016 /$ j.matdes.2009.06.034

[20] Szentes A., Horváth G.: Role of catalyst support int he growth of multi-walled carbon nanotubes. Hungarian Journal of Industrial Chemistry, 36, 113-117 (2008).

[21] Boudenne A., Ibos L., Gehin E., Candau Y.: A simultaneous characterization of thermal conductivity and diffusivity of polymer materials by a periodic method. Journal of Physics D: Applied Physics, 37, 132-139 (2004).

DOI: $10.1088 / 0022-3727 / 37 / 1 / 022$

[22] Brunauer S., Emmett P. H., Teller E.: Adsorption of gases in multimolecular layers. Journal of the American Chemical Society, 60, 309-319 (1938). DOI: $10.1021 / \mathrm{ja} 01269 \mathrm{a} 023$

[23] Barrett P., Joyner L. G., Halenda P. P.: The determination of pore volume and area distributions in porous substances. I. Computations from nitrogen isotherms. Journal of the American Chemical Society, 73, 373380 (1951).

DOI: $10.1021 / \mathrm{ja} 01145 \mathrm{a} 126$

[24] Lee S. H., Cho E. N. R., Jeon S. H., Youn J. R.: Rheological and electrical properties of polypropylene composites containing functionalized multi-walled carbon nanotubes and compatibilizers. Carbon, 45, 2810-2822 (2007).

DOI: $10.1016 /$ j.carbon.2007.08.042

[25] Jin S. H., Park Y-B., Yoon K. H.: Rheological and mechanical properties of surface modified multiwalled carbon nanotube-filled PET composite. Composites Science and Technology, 67, 3434-3441 (2007). DOI: 10.1016/j.compscitech.2007.03.013

[26] Xiao K. Q., Zhang L. C., Zarudi I.: Mechanical and rheological properties of carbon nanotube-reinforced polyethylene composites. Composites Science and Technology, 67, 177-182 (2007). DOI: 10.1016/j.compscitech.2006.07.027

[27] Pötschke P., Fornes T. D., Paul D. R.: Rheological behavior of multiwalled carbon nanotube/polycarbonate composites. Polymer, 43, 3247-3255 (2002). DOI: $10.1016 / \mathrm{S} 0032-3861(02) 00151-9$

[28] Prashantha K., Soulestin J., Lacrampe M. F., Krawczak P., Dupin G., Claes M.: Masterbatch-based multiwalled carbon nanotube filled polypropylene nanocomposites: Assessment of rheological and mechanical properties. Composites Science and Technology, 69, 1756-1763 (2009).

DOI: 10.1016/j.compscitech.2008.10.005 